\title{
A CONTRALATERAL EYE STUDY COMPARING APODIZED DIFFRATIVE AND FULL DIFFRATIVE LENSES: WAVEFRONT ANALYSIS AND DISTANCE AND NEAR UNCORRECTED VISUAL ACUITY
}

\author{
Marcony Rodrigues de Santhiago, ${ }^{\mathrm{I} I \mathrm{II}}$ Marcelo Vieira Netto, ${ }^{\mathrm{II}}$ Jackson Barreto

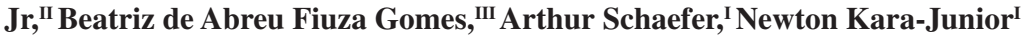

doi: 10.1590/S1807-59322009001000004

\begin{abstract}
Santhiago MR, Netto MV, Barreto Jr J, Gomes BAF, Schaefer A, Kara-Junior N. A contralateral eye study comparing apodized diffrative and full diffrative lenses: wavefront analysis and distance and near uncorrected visual acuity. Clinics. 2009;64(10):953-60.
\end{abstract}

PURPOSE: To evaluate intraindividual visual acuity, wavefront errors and modulation transfer functions in patients implanted with two diffractive multifocal intraocular lenses.

METHODS: This prospective study examined 40 eyes of 20 cataract patients who underwent phacoemulsification and implantation of a spherical multifocal ReSTOR intraocular lens in one eye and an aspheric Tecnis ZM900 multifocal intraocular lens in the other eye. The main outcome measures, over a 3-month follow-up period, were the uncorrected photopic distance and near visual acuity and the defocus curve. The visual acuity was converted to logMAR for statistical analysis and is presented in decimal scale. The wavefront error and modulation transfer function were also evaluated in both groups.

RESULTS: At the 3-month postoperative visit, the mean photopic distance uncorrected visual acuity (UCVA) was $0.74 \pm 0.20$ in the ReSTOR group and $0.76 \pm 0.22$ in the Tecnis group $(p=0.286)$. The mean near UCVA was $0.96 \pm 0.10$ in the ReSTOR group and $0.93 \pm 0.14$ in the Tecnis group ( $p=0.963$ ). The binocular defocus curve showed measurements between the peaks better than $0.2 \log$ MAR. The total aberration, higher-order aberration and coma aberration were not significantly different between the groups. The spherical aberration was significantly lower in the Tecnis group than in the ReSTOR group. ( $p=0.004)$. Both groups performed similarly for the modulation transfer function.

CONCLUSION: The ReSTOR SN60D3 and Tecnis ZM 900 intraocular lenses provided similar photopic visual acuity at distance and near. The diffractive intraocular lenses studied provided a low value of coma and spherical aberrations, with the Tecnis intraocular lens having a statistically lower spherical aberration compared to the ReSTOR intraocular lens. In the $5 \mathrm{~mm}$ pupil diameter analyses, both intraocular lens groups showed similar modulation transfer functions.

KEYWORDS: Multifocal intraocular lenses; Aberrometer; Wavefront; Modulation transfer function; Visual acuity.

\section{INTRODUCTION}

In an attempt to alleviate the physiological phenomenon

\footnotetext{
${ }^{\text {I }}$ Department of Cataract Surgery, Universidade de São Paulo - São Paulo/ SP, Brazil.

II Department of Refractive Surgery, Universidade de São Paulo - São Paulo/ SP, Brazil.

III Department of Ophthalmology, Universidade Federal do Rio de Janeiro - Rio de Janeiro/RJ, Brazil.

Email: marconysanthiago@hotmail.com

Tel.: 55113069.7873

Received for publication on May 04, 2009

Accepted for publication on July 07, 2009
}

of accommodation loss, which occurs with aging, diffractive optics has been found to be effective for multifocal intraocular lenses (IOLs). With modern techniques, manufacturers are not only concerned with the far and near foci, but they also aim to optimize the image quality with more complex IOL surfaces. ${ }^{1-8}$

Considering that the amount of intraocular light scattering and higher-order aberrations, due to refractive or diffractive optics, may lead to a poor retinal image quality, aspheric treatment, in the form of aspheric modified prolate IOL surfaces, has been added to reduce the total amount of spherical aberration in the eye and to improve 
the optical quality. ${ }^{1-13}$ The multifocal diffractive IOL Tecnis ZM900, based on the Huygens-Fresnel principle, has a prolate aspheric anterior surface that reduces spherical aberrations. ${ }^{8,12}$ The multifocal diffractive ReSTOR SN60D3 lens has a central 3.6-mm apodized optic region where 12 concentric diffractive zones on the anterior surface have a gradual reduction in diffractive step height from the center to the periphery. ${ }^{14,15}$

Since aberrometers measure the shape of a wavefront of light that has propagated through the eye's optical system they provide an objective measurement of optical aberrations that include sphere and cylinder, as well as other distortions such as spherical aberrations, coma, or other higher-order aberrations. Wavefront sensors also provide image quality metrics such as the modulation transfer function (MTF), which displays the ratio of image contrast to object contrast for ocular optics as a function of the spatial frequency of a sinusoidal grating. ${ }^{16-21}$

The aim of this prospective clinical trial is to compare visual performance between a pseudophakic eye with a spherical apodized diffractive multifocal IOL and the other pseudophakic eye with an aspheric diffractive multifocal IOL using the uncorrected distance and near visual acuity, wavefront analysis and the modulation transfer function as outcomes.

\section{METHODS}

This prospective comparative clinical study included both eyes of 20 patients, for a total of 40 eyes. After approval by the ethics committee, 20 patients older than 40 years of age with bilateral, visually significant cataracts were enrolled consecutively; the patients received a multifocal IOL Tecnis ZM900 lens in one eye (20 eyes; Advanced Medical Optics) and a spheric multifocal AcrySof ReSTOR SN60D3 lens (20 eyes; Alcon Laboratories) in the other eye. Informed consent was obtained, and the study adhered to the tenets of the Declaration of Helsinki.

Patients with bilateral, visually significant cataracts with corneal astigmatism lower than $1.0 \mathrm{D}$ (diopters) were eligible for inclusion in the study. Exclusion criteria were any other ocular diseases, such as corneal opacities or irregularity, dry eye, amblyopia, anisometropia, glaucoma, retinal abnormalities, surgical complications, IOL tilt, IOL decentration greater than $0.4 \mathrm{~mm}$ (estimated by retroillumination) or incomplete follow-up.

The patients were examined before surgery and at 1, 7, 30 and 90 days after surgery. At 90 days postoperation, the distance $(4 \mathrm{~m})$ and near $(0.4 \mathrm{~m})$ uncorrected visual acuities (UCVAs) were measured, as well as the higher-order aberration values and modulation transfer function curve.
The visual acuity was measured using the Early Treatment of Diabetic Retinopathy Study charts under photopic conditions (target luminance of $90 \mathrm{~cd} / \mathrm{m}^{2}$ ). The visual acuity values were converted to the logarithm of the minimal angle resolution scale (logMAR) for statistical analysis and are therefore presented in decimal scale.

A defocus curve for each multifocal IOL group was obtained according to previous studies ${ }^{6,22-24}$ by plotting the mean monocular and binocular visual acuities against 14 values of defocus (ranging from +2.0 to $-5.0 \mathrm{D}$ in $0.5 \mathrm{D}$ steps). The pseudo-accommodative amplitude was determined with a subjective trial lens-induced accommodation method.

The wavefront analysis and modulation transfer function curve were obtained using the iTrace aberrometer (Tracey Technologies, Houston, TX), which uses ray tracing technology to obtain the wavefront data. All aberrations were measured up to the sixth Zernike order. The modulation transfer function curves were obtained by considering the mean value for each spatial frequency of each IOL. The measurements were repeated at least three times to obtain a well-focused aligned image of the eye. Measurements were also taken for the maximum pupil diameter, and the data were then collected and analyzed for a pupil diameter of $5.0 \mathrm{~mm}$. The pupils were dilated with two drops of cyclopentolate (10\%) given 15 minutes apart. The measurements were taken 45 minutes after the second cyclopentolate drop was administered. The pupil diameter was measured using the Colvard pupillometer (Oasis Medical, Glendora, CA).

All surgeries were performed by one experienced surgeon using standardized small-incision phacoemulsification with the IOL implantation in the capsular bag. A continuous curvilinear capsulorhexis with an approximate $5.0 \mathrm{~mm}$ diameter was created. No adverse events were reported.

Statistical analysis was performed using SPSS for Windows (version 115, SPSS). All statistical tests were conducted at an alpha level of 0.05 . The analysis was based on a non-normal distribution of the data. The two IOLs were compared between the eyes intraindividually. The nonparametric Wilcoxon paired test was used to compare data between the two IOL groups.

\section{RESULTS}

A total of 20 patients (12 men [60.0\%] and 8 women [40.0\%]) were enrolled in this study. No significant difference was found among the IOL groups for the mean IOL power $(p=0.923)$.

At 3 months postoperation, all eyes showed improvement in the uncorrected visual acuity (UCVA). The spherical 
equivalent was $+0.21 \pm 0.17$ in the ReSTOR group and +0.22 \pm 0.17 in the Tecnis group ( $p=0.840$ ). The mean distance UCVA was $0.74 \pm 0.20$ in the ReSTOR group and $0.76 \pm$ 0.22 in the Tecnis group. There was no significant difference among the IOL groups for distance UCVA $(p=0.286)$. The mean near UCVA was $0.96 \pm 0.10$ in the ReSTOR group and $0.93 \pm 0.14$ in the Tecnis group. No significant difference was found between the ReSTOR and Tecnis groups $(p=0.963)$ (Table 1).

The results of the defocus curve for both IOL groups and the binocular defocus curve are shown in Figure 1. The Tecnis group showed two peaks at 0.0 and 3.0, and the ReSTOR group showed two peaks at 0.0 and 3.5. When
-2.00 trial lenses were anteposed, simulating an intermediate target condition, both groups exhibited a visual acuity better than $0.4 \log$ MAR. The binocular defocus curve showed a better performance at the intermediate distance with values better than $0.2 \log$ MAR between the two peaks.

The postoperative wavefront analysis (Table 2) revealed total aberration root-mean-square (RMS) values of $0.56 \pm 0.23$ $\mu \mathrm{m}$ (Tecnis) and $0.75 \pm 0.76 \mu \mathrm{m}$ (ReSTOR). No statistically significant difference was found between the ReSTOR and Tecnis groups $(p=0.737)$. The mean higher-order aberration values were $0.34 \pm 0.19 \mu \mathrm{m}$ (Tecnis) and $0.46 \pm 0.63 \mu \mathrm{m}$ (ReSTOR). No statistically significant difference was found between the two IOL groups ( $p=0.575)$.

Table 1 - Visual performance of diffractive multifocal IOLs

\begin{tabular}{lcccccc}
\hline Intraocular lens & $n$ & $\begin{array}{c}\text { Distance uncorrected } \\
\text { visual acuity }\end{array}$ & $\begin{array}{c}\text { Distance corrected } \\
\text { visual acuity }\end{array}$ & $\begin{array}{c}\text { Near uncorrected } \\
\text { visual acuity }\end{array}$ & $\begin{array}{c}\text { Near corrected } \\
\text { visual acuity }\end{array}$ & $\begin{array}{c}\text { Spherical } \\
\text { equivalent }\end{array}$ \\
\hline ReSTOR & 20 & $0.74 \pm 0.20$ & $1.00 \pm 0.00$ & $0.96 \pm 0.10$ & $1.00 \pm 0.00$ & $0.21 \pm 0.17$ \\
Tecnis & 20 & $0.76 \pm 0.22$ & $1.00 \pm 0.00$ & $0.93 \pm 0.14$ & $1.00 \pm 0.00$ & $0.22 \pm 0.17$ \\
$P$ value & & 0.286 & & 0.963 & 0.840 \\
\hline
\end{tabular}

The visual acuity values were converted to the logarithm of the minimal angle resolution scale (logMAR) for statistical analysis and are thus presented in decimal scale \pm standard deviation.

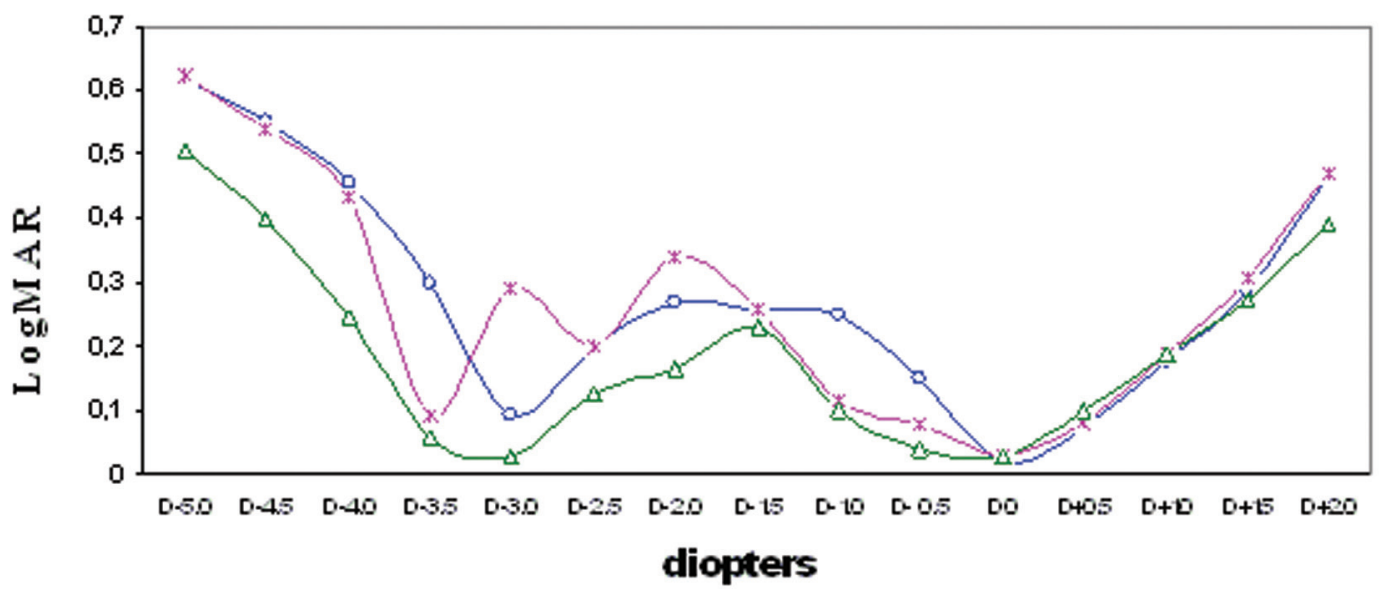

- Tecnis - - Restor - Bnocular

Figure 1 - Visual acuity at various defocusing levels in the ReSTOR group and Tecnis group. The values are the mean of the logMAR visual acuity. The binocular defocusing curve showed a good range for the pseudo-accommodative amplitude

Table 2 - Wavefront data with $5 \mathrm{~mm}$ pupil diameter

\begin{tabular}{lccc}
\hline & \multicolumn{2}{c}{ Mean $(\mu \mathrm{m}) \pm \mathrm{SD}$} & $P$ value \\
\cline { 2 - 3 } & ReSTOR & Tecnis & 0.575 \\
HOA RMS & $0.46 \pm 0.63 \mu \mathrm{m}$ & $0.34 \pm 0.19 \mu \mathrm{m}$ & 0.455 \\
Coma aberration RMS & $0.17 \pm 0.16 \mu \mathrm{m}$ & $0.16 \pm 0.07 \mu \mathrm{m}$ & $0.004 *$ \\
Spherical aberration RMS & $0.08 \pm 0.07 \mu \mathrm{m}$ & $0.03 \pm 0.03 \mu \mathrm{m}$ & 0.737 \\
Total aberration RMS & $0.75 \pm 0.76 \mu \mathrm{m}$ & $0.56 \pm 0.23 \mu \mathrm{m}$ & \\
\hline
\end{tabular}

$\mathrm{HOA}=$ higher-order aberration; RMS = root mean square; $\mathrm{SD}=$ standard deviation; $*$ = statistically significant. 
When analyzing the higher-order aberrations separately (Figure 2), the coma values were $0.16 \pm 0.07 \mu \mathrm{m}$ (Tecnis) and $0.17 \pm 0.16 \mu \mathrm{m}$ (ReSTOR). No statistically significant difference was found between the groups $(p=0.455)$. The spherical aberration values were $0.03 \pm 0.03 \mu \mathrm{m}$ (Tecnis) and $0.08 \pm 0.07 \mu \mathrm{m}$ (ReSTOR). The Tecnis IOL showed a significantly lower value for the spherical aberration when compared to the ReSTOR IOL ( $p=0.004$ ).

The postoperative modulation transfer function curves were obtained for each IOL group. No statistically significant difference was found between the Tecnis and ReSTOR groups for all spatial frequencies (Figure 3). The iTrace aberrometer software used to generate the MTF curve also provided the average height for each MTF curve studied. The mean MTF value for each multifocal IOL was $0.278 \pm 0.099$ (Tecnis) and $0.252 \pm 0.112$ (ReSTOR). No statistically significant difference was found between the Tecnis and ReSTOR groups $(p=0.502)$.

\section{DISCUSSION}

New IOL designs, including aspheric modified prolate surfaces, aim to reduce the total amount of spherical aberration in the eye,,$^{21,25-27}$ thereby improving visual quality. However, the combination of far, intermediate and near visual correction with an acceptable optical quality is quite challenging. ${ }^{28-29}$

Since the incoming light through a multifocal IOL generates out-of-focus images that overlap the distant focus image, the image sharpness is generally compromised. In this study, the intraocular optical quality of the diffractive multifocal IOLs was compared using wavefront data and modulation transfer curves that were analyzed with 5.0 $\mathrm{mm}$ pupil diameters. In an effort to minimize other effects related to each patient's eyes, an apodized diffractive AcrySof SN60D3 ReSTOR was used in one eye, and the full diffractive Tecnis ZM900 was used in the other eye.

\section{Visual outcomes}

The Tecnis and ReSTOR IOLs performed similarly in the uncorrected visual acuity for the far and near distances. The two IOLs had a different performance in the defocus curve, with a range of pseudo-accommodative amplitudes

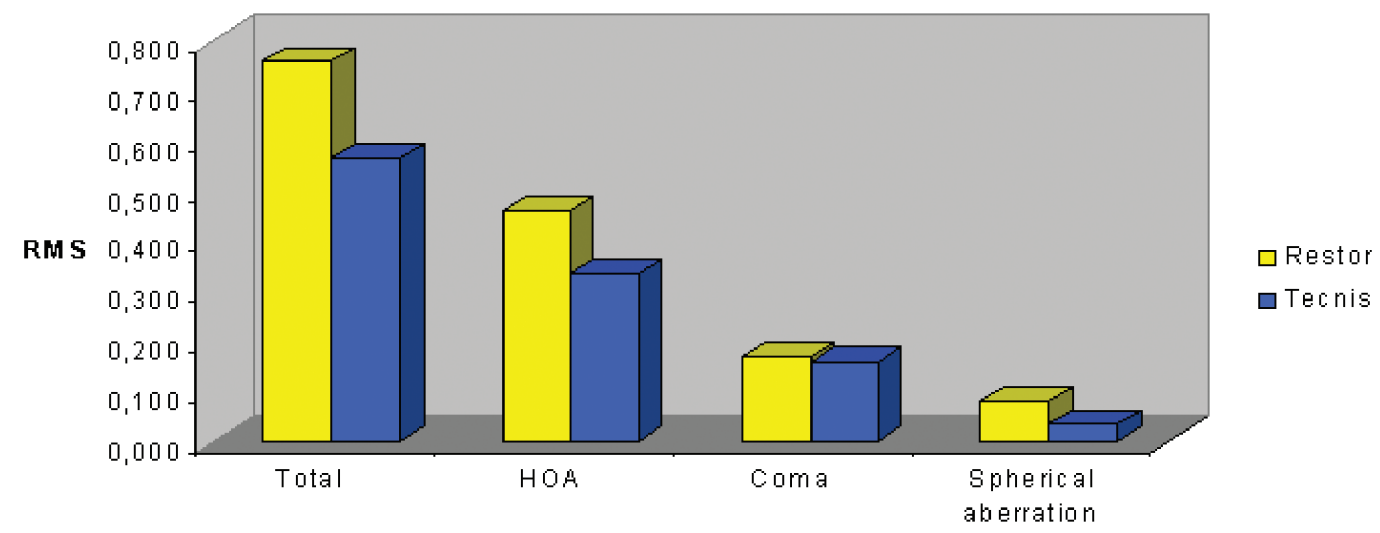

Figure 2 - Bar graph showing the wavefront data with a $5 \mathrm{~mm}$ pupil diameter for two diffractive multifocal intraocular lenses . The root-mean-square of the total aberration, the higher-order aberration (HOA) and coma aberration were not statistically different between the groups. The spherical aberration was significantly lower in the Tecnis group than in the ReSTOR group ( $p=0.004)$

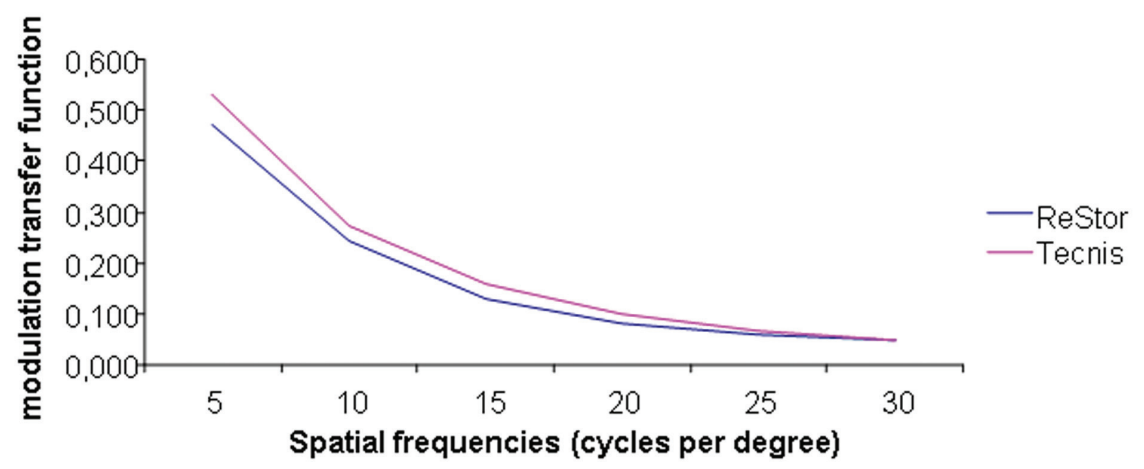

Figure 3 - The modulation transfer function (MTF) curve analyzed for a $5 \mathrm{~mm}$ pupil diameter of the IOL groups at different spatial frequencies. The MTF shows the contrast transferred at different spatial frequencies. The aspheric full diffractive multifocal IOL Tecnis ZM900 performed similar to the spherical apodized diffractive multifocal ReSTOR ( $p>0.05$ at all spatial frequencies studied) 
better than $0.4 \log$ MAR. The depth of focus seems to be better bilaterally compared to the range of focus of each IOL studied separately. Although not representative of daily activities, the binocular defocusing test, with a mix and match strategy may represent an option for patients who want to be free of glasses.

Using the defocus curve, this study showed that the Tecnis IOL performed better than the ReSTOR IOL for intermediate distances of 50 and $100 \mathrm{~cm}$, as previous research ${ }^{22}$ has also shown. Cilino et al. ${ }^{6}$ also compared patients implanted binocularly with refractive and diffractive IOLs, and using the mean binocular defocusing curves, they have shown that the diffractive multifocal IOL group (Tecnis, in their case) exhibited a better trend with respect to the refractive (Array and ReZoom) multifocal IOL groups.

\section{Spherical Aberration}

Intraocular lenses with spherical surfaces contribute to increasingly positive spherical aberrations in the human eye. The aspheric IOLs reduce the total amount of the fourth order Zernike aberration, or the spherical aberration. In our study, a low spherical aberration error was observed in the aspheric IOL compared to a conventional spherical IOL, as previously reported by other authors. ${ }^{21,25-27,30,31}$ Although both IOLs showed low values of spherical aberrations, the Tecnis IOL performed better than the ReSTOR IOL $(p=$ 0.004). The results in our study agree with those of Toto et al. $^{22}$ : the spherical aberration values were lower with the full diffractive IOL than with the apodized diffractive multifocal IOL.

The spheric ReSTOR IOLs tend to increase the spherical aberration levels due to their less prolate periphery compared to the Tecnis aspheric design. Nevertheless, the apodized diffractive surface of the ReSTOR IOL probably behaves as an aspheric surface. It progressively decreases the height of the diffractive steps from the center to the periphery, showing less spherical aberration. ${ }^{14,15,22,32-34}$ In addition to the apodized center, the diffractive portion turns into a pure refractive lens at the periphery, which tends to suppress night visual disturbances such as halos and glare. ${ }^{15}$

In our study, the mean value of the spherical aberration $(0.08 \mu \mathrm{m} \pm 0.18)$ for the multifocal ReSTOR IOL was similar to the results of several other studies, such as Zelichowska et al. ${ }^{34}(0.09 \mu \mathrm{m} \pm 0.00$ analyzed 6 months after surgery), Souza et al. ${ }^{15}(0.09 \mu \mathrm{m} \pm 0.05$ analyzed 3 months after surgery) and Rocha et al. ${ }^{32}(0.09 \mu \mathrm{m} \pm 0.05$ analyzed 2 months after surgery). However, Toto et al. ${ }^{22}$ found a higher level of spherical aberration $(0.13 \mu \mathrm{m} \pm 0.04$ analyzed 6 months after surgery). Although all of these studies used a $5 \mathrm{~mm}$ pupil diameter for data analysis, they used different aberrometer devices, and therefore different technologies, to obtain the wavefront data. It is important to mention that the wavefront data from the diffractive multifocal IOL should be used with caution. ${ }^{34-36}$

According to Charman et al., ${ }^{35,36}$ the simultaneous distribution of light on the far and near foci means that two wavefronts of different curvature emerge from the IOL; therefore, it is more difficult for the aberrometer to locate the sample centroids, from which the aberration values are derived. Although we found results similar to other studies using the ray tracing technology, Charman et al. ${ }^{35,36}$ demonstrated that the Hartmann-Shack aberrometers, which use longer wavelengths of infrared light, are more likely to produce satisfactory results for eyes with diffractive IOLs.

\section{Coma aberrations}

Spherical aberrations and coma aberrations are the higher-order aberrations that contribute the most to visual disturbances and dissatisfaction in patients following the implantation of a multifocal IOL. Although not statistically significant, a smaller number of coma aberrations were detected in the Tecnis eyes than in the ReSTOR eyes ( $p=$ $0.455)$.

Coma aberrations provide information on whether the IOL is properly centered. Dietze et al..$^{37}$ suggested that correcting the spherical aberration with aspheric IOLs could produce more coma aberrations when the IOL is not centered. This leads us to conclude, indirectly, that our lower rates of decentration could justify the lower incidence of coma aberration errors in both groups. However, a longer follow-up would be more appropriate for this analysis because the asymmetric contraction of a fibrotic capsule could develop and decenter the implanted IOL, as has been demonstrated by several authors..$^{38-40}$

\section{Modulation transfer function}

The modulation transfer function defines how optical systems (e.g., the IOL in this study) modulate the contrast sensitivity as a function of spatial frequency. In this study, the mean MTF curve was obtained for each IOL group at a $5 \mathrm{~mm}$ pupil diameter. Comparing the multifocal diffractive IOLs, the aspheric multifocal Tecnis IOL performed similarly to the apodized multifocal ReSTOR IOL. With the $5 \mathrm{~mm}$ analysis, the apodization of the surface may lead the ReSTOR IOL to behave as an aspheric IOL, which could explain its performance in the modulation of contrast.

Choi and Schwiegerling ${ }^{41}$ measured the optical properties of multifocal diffractive Tecnis, apodized diffractive ReSTOR and refractive ReZoom IOLs. They concluded that, 
under dark conditions, the shift in the optical performance of the apodized diffractive lens towards distance vision reduces the artifacts that appear under night driving conditions. These artifacts remain for the zonal refractive and fullaperture diffractive lenses. They also demonstrated that, for 6 mm pupil diameters, the apodized diffractive IOLs shift their performance from near vision to distance vision, whereas the zonal refractive and full-aperture diffractive IOLs continue to balance performance between the far and near distance.

Ortiz et al. ${ }^{33}$ studied the modulation transfer function of two multifocal IOLs, a refractive ReZoom and an apodized diffractive ReSTOR (AcrySof). Unlike our study that analyzed the mean curve of each IOL group with a $5 \mathrm{~mm}$ pupil diameter, they studied the spatial frequencies at the $0.5 \mathrm{MTF}$ and the cutoff MTF of the different curves of the IOLs with $3 \mathrm{~mm}$ and $5 \mathrm{~mm}$ pupil diameters. They found that the pupil diameter had a greater influence on the $0.5 \mathrm{MTF}$ value than on the cutoff MTF value for all IOLs. The 0.5 MTF value was the highest in the AcrySof ReSTOR group with both pupil diameters. The difference in the cutoff MTF values between the groups was not statistically significant with either pupil size. Our study was not designed to specifically use the 0.5 and the cutoff MTF values; rather, we chose to study the curve described by each IOL group.

A limitation of our study was that the MTF measurements were done with only a $5.0 \mathrm{~mm}$ pupil diameter. In future studies, the modulation transfer function measurements could be done at varying pupil sizes. In addition, subjective questionnaires were not used in this study, which may give a more realistic evaluation of daily living.

In a study with a model eye, Artigas et al. ${ }^{42}$ showed that the MTF curves varied according to the pupil size, mainly if a refractive multifocal IOL was studied, which was not the case in the present study. Examining the distance focus with small pupils ( 2.0 to $3.5 \mathrm{~mm}$ ), the previous study has shown that the MTF curve of the refractive multifocal IOL
(ReZoom) was noticeably higher than the curve of the multifocal IOLs (ReSTOR and Tecnis ZM900) at all spatial frequencies. Furthermore, when examining the distance focus with larger pupils ( 4.0 to $5.0 \mathrm{~mm}$ ), the MTF curve of the ReZoom IOL was similar to the curves of the other two multifocal IOLs (ReSTOR and Tecnis).

One other limitation of the present study is that the iTrace aberrometer device performs monochromatic measurements, and these results cannot be compared to human polychromatic vision. Although the diffractive IOLs have a high chromatic aberration, they can nevertheless function well in the human eye because the amount of this chromatic aberration is approximately the same, albeit with opposite sign, as the aberration in the refractive part of the eye (cornea and IOL). It also should be noted that, although the results of the iTrace aberration device could be influenced by the near addition power of the investigated IOLs, as the different near additions cause different patterns of the observed blurred points, the results of the MTF curve were similar between the multifocal IOLs studied.

In conclusion, the in vivo assessment of the multifocal IOL performance provides useful objective information about IOL optical quality in vivo. In our study, the contrast transferred for a $5 \mathrm{~mm}$ pupil diameter was similar for the diffractive multifocal IOLs, Tecnis ZM900 and ReSTOR. The wavefront assessment showed a lower spherical aberration with both multifocal IOLs, although mainly with the Tecnis IOL. According to this study, both of the diffractive multifocal IOLs studied provide similar distance and near visual acuities. The range of the pseudoaccommodative amplitude seems to be better with the mix and match strategy; however, further assessment of the IOL improvements, such as the combination of asphericity and apodization, will provide important information and help us to make a better preoperative decision regarding the choice of the IOL.

\section{REFERENCES}

1. Javitt JC, Wang F, Trentacost DJ, Rowe M, Tarantino N. Outcomes of cataract extraction with multifocal intraocular lens implantation; functional status and quality of life. Ophthalmology. 1997;104:589-9.

2. Javitt JC, Steinert RF. Cataract extraction with multifocal intraocular lens implantation; a multinational clinical trial evaluating clinical. functional and quality-of-life outcomes. Ophthalmology. 2000;107:2040-8.
3. Pieh S, Marvan P, Lackner B, Hanselmayer G, Schmidinger G, Leitgeb $\mathrm{R}$, et al. Quantitative performance of bifocal and multifocal intraocular lenses in a model eye: point spread function in multifocal intraocular lenses. Arch Ophthalmol. 2002;120:23-8.

4. Chang DF. Prospective functional and clinical comparison of bilateral ReZoom and ReSTOR intraocular lenses in patients 70 years or younger. J Cataract Refract Surg. 2008;34:934-41. 
5. Alió JL, Schimchak P, Montés-Micó R, Galal A. Retinal image quality after microincision intraocular lens implantation. J Cataract Refract Surg. 2005;31:1557-60.

6. Cillino S, Casuccio A, Di Pace F, Morreale R, Pillitteri F, Cillino G, et al. One-year outcomes with new-generation multifocal intraocular lenses. Ophthalmology. 2008;115:1508-16.

7. Chiam PJ, Chan JH, Haider SI, Karia N, Kasaby H, Aggarwal RK. Functional vision with bilateral ReZoom and ReSTOR intraocular lenses 6 months after cataract surgery. J Cataract Refract Surg. 2007;33:205761.

8. Pepose JS, Qazi MA, Davies J, Doane JF, Loden JC, Sivalingham V, et al. Visual performance of patients with bilateral vs combination Crystalens. ReZoom. and ReSTOR intraocular lens implants. Am J Ophthalmol. 2007;144:347-57.

9. Campbell FW, Green DG. Optical and retinal factors affecting visual resolution. J Physiol. 1965;181:576-93.

10. Thibos LN, Hong X, Bradley A, Applegate RA. Accuracy and precision of objective refraction from wavefront aberrations. J Vis. 2004;4:329-51.

11. Applegate, Limits to vision: can we do better than nature? J Refract Surg. 16 (2000), pp. 547-51.

12. Packer M, Fine IH, Hoffman RS, Piers PA. Improved functional vision with a modified prolate intraocular lens. J Cataract Refract Surg. 2004;30:986-92.

13. Bellucci R. Multifocal intraocular lenses. Curr Opin Ophthalmol. 2005;16:33-7.

14. Davison JA. Simpson MJ. History and development of the apodized diffractive intraocular lens. J Cataract Refract Surg. 2006;32:849-58.

15. Souza CE, Muccioli C, Soriano ES, Chalita MR, Oliveira F, Freitas LL, et al. Visual performance of AcrySof ReSTOR apodized diffractive IOL: a prospective comparative trial. Am J Ophthalmol. 2006;141:827-32.

16. Lane SS, Morris M, Nordan L, Packer M, Tarantino N, Wallace RB 3rd, et al. Multifocal intraocular lenses. Ophthalmol Clin North Am. 2006;19:89-105.

17. Applegate RA. Glenn Fry award lecture 2002: wavefront sensing. ideal corrections. and visual performance. Optom Vis Sci 2004;81:167-77.

18. Applegate R. Hilmantel G. Thibos L. Assessment of visual performance (Chapter 7). In: Krueger R. Applegate RA. MacRae S. editors. Wavefront customized visual correction: the quest for super vision. 2nd ed. New Jersey: Slack. Inc. 2004:65-76.

19. Applegate RA, Thibos LN, Hilmantel G. Optics of aberroscopy and super vision. J Cataract Refract Surg. 2001;27:1093-107.

20. Kawamorita T, Uozato H. Modulation transfer function and pupil size in multifocal and monofocal intraocular lenses in vitro. J Cataract Refract Surg $2005 ; 31: 2379-85$.

21. Rawer R, Stork W, Spraul CW, Lingenfelder C. Imaging quality of intraocular lenses. J Cataract Refract Surg 2005; 31:1618-31.

22. Toto L, Falconio G, Vecchiarino L, Scorcia V, Di Nicola M, Ballone $\mathrm{E}$, et al. Visual performance and biocompatibility of 2 multifocal diffractive IOLs: six-month comparative study. J Cataract Refract Surg. 2007;33:1419-25.
23 Bellucci R, Giardini P. Pseudoaccommodation with the 3M diffractive multifocal intraocular lens: a refraction study of 52 subjects. J Cataract Refract Surg 1993;19:32-5.

24. Sauder G, Degenring RF, Kamppeter B, Hugger P. Potential of the $1 \mathrm{CU}$ accommodative intraocular lens. Br J Ophthalmol. 2005;89:1289-92.

25. Bellucci R, Morselli S, Piers P. Comparison of wavefront aberrations and optical quality of eyes implanted with five different intraocular lenses. J Refract Surg. 2004; 20:297-306.

26. Holladay JT, Piers PA, Koranyi G, van der Mooren M, Norrby NE. A new intraocular lens design to reduce spherical aberration of pseudophakic eyes. J Refract Surg. 2002;18:683-91.

27. Franchini A. Compromise between spherical and chromatic aberration and depth of focus in aspheric intraocular lenses. J Cataract Refract Surg. 2007;33:497-509.

28. Pepose JS. Maximizing Satisfaction with Presbyopia-Correcting Intraocular Lenses: The Missing Links. Am J Ophthalmol. 2008;146:6418.

29. Kohnen T. Multifocal IOL technology: A successful step on the journey toward presbyopia treatment. J Cataract Refract Surg. 2008;34:2005.

30. Rohart C, Lemarinel B, Hoang-Xuan T, Gatinel D. Ocular aberrations after cataract surgery with hydrophobic and hydrophilic acrylic intraocular lenses; comparative study. J Cataract Refract Surg 2006;32:1201-05

31. Pesudovs K, Dietze H, Stewart OG, Noble BA, Cox MJ. Effect of cataract surgery incision location and intraocular lens type on ocular aberrations. J Cataract Refract Surg. 2005;31:725-34.

32. Rocha KM, Chalita MR, Souza CE, Soriano ES, Freitas LL, Muccioli $\mathrm{C}$, et al. Postoperative wavefront analysis and contrast sensitivity of a multifocal apodized diffractive IOL (ReSTOR) and three monofocal IOLs. J Refract Surg. 2005;21:808-12.

33. Ortiz D, Alió JL, Bernabéu G, Pongo V.. Optical performance of monofocal and multifocal intraocular lenses in the human eye. J Cataract Refract Surg. 2008;34:755-62.

34. Zelichowska B, Rekas M, Stankiewicz A, Cerviño A, Montés-Micó R. Apodized diffractive versus refractive multifocal intraocular lenses: Optical and visual evaluation. J Cataract Refract Surg. 2008;34:2036-42.

35. Charman WN, Montés-Micó R, Radhakrishnan H. Can we measure wave aberration in patients with diffractive IOLs? J Cataract Refract Surg. 2007;33:1997.

36. Charman WN, Montés-Micó R, Radhakrishnan H. Problems in the measurement of wavefront aberration for eyes implanted with diffractive bifocal and multifocal intraocular lenses. J Refract Surg. 2008;24:280-6.

37. Dietze HH. Cox MJ. Limitations of correcting spherical aberration with aspheric intraocular lenses. J Refract Surg. 2005;21:541-6.

38. Mamalis N, Crandall AS, Pulsipher MW, Follett S, Monson MC Intraocular lens explantation and exchange: a review of lens styles. clinical indications. clinical results. and visual outcome. J Cataract Refract Surg. 1991;17:811-8.

39. Hayashi K, Hayashi H, Matsuo K, Nakao F, Hayashi F. Anterior capsule contraction and intraocular lens dislocation after implant surgery in eyes with retinitis pigmentosa. Ophthalmology. 1998;105:1239-43. 
40. Hayashi H. Hayashi K. Nakao F. Hayashi F. Anterior capsule contraction and intraocular lens dislocation in eyes with pseudoexfoliation syndrome. Br J Ophthalmol. 1998;82:1429-32.

41. Choi J. Schwiegerling J. Optical performance measurement and night driving simulation of ReSTOR. ReZoom. and Tecnis multifocal intraocular lenses in a model eye. J Refract Surg. 2008;24:218-22.
42. Artigas JM. Menezo JL. Peris C. Felipe A. Díaz-Llopis M. Image quality with multifocal intraocular lenses and the effect of pupil size: comparison of refractive and hybrid refractive-diffractive designs. J Cataract Refract Surg. 2007;33:2111-7. 